\title{
UNA REVISIÓN DEL CONTRATO DE ARRENDAMIENTO DE EMPRESA EN EL ÁMBITO DE LA GESTIÓN HOTELERA.
}

\author{
$\mathrm{M}^{\mathrm{a}}$ TERESA OTERO COBOS ${ }^{1}$ \\ Doctora en Derecho y abogada \\ Área de Derecho Mercantil. Universidad de Málaga
}

\begin{abstract}
Resumen
La industria hotelera es uno de los motores económicos del mundo. Los propietarios de establecimientos hoteleros eligen a terceros para encomendarles la gestión de su negocio con la finalidad de aumentar sus beneficios. Cada contrato de explotación posee sus propias características. Este artículo ofrece una visión del contrato de arrendamiento de empresa hotelera.
\end{abstract} contrato.

Palabras Clave: Derecho, turismo, gestión, cadena hotelera, arrendamiento,

\section{Abstract}

The hotel industry is one of the most important world's economic engine. Hotel owners choose a third-party operator to run their hotel company to provide value and increase profitability. Each management agreement has its own features. This article aims to provide an overview of lease agreement.

Key words: Law, tourism, management, hotel chain, lease, agreement.

\section{CONSIDERACIONES PREVIAS}

El negocio hotelero ha evolucionado notablemente desde sus inicios hasta nuestros días. Los sistemas de gestión han cambiado según lo hacía el entorno político, económico, social y territorial. Es decir, en sus comienzos el mercado hotelero estaba gestionado directamente por la propiedad, generalmente familias que asumían el control total y la toma absoluta de decisiones en el negocio. Esto ha permitido una importante especialización y experiencia en el sector que se ha traducido en la creación de cadenas hoteleras gracias a la adquisición de un mayor número de establecimientos. El modo de incorporar estos nuevos establecimientos ha pasado con el tiempo a evitar la propiedad para fomentar la colaboración empresarial mediante otros modelos contractuales.

En esta transformación de los regímenes de gestión se ha extendido cada vez más el modelo americano ${ }^{2}$. Este modelo no se centra en la inversión directa, sino que la explotación se desarrolla mediante acuerdos contractuales como el arrendamiento, la franquicia o la gestión. En lo que se refiere al modelo europeo, las compañías de origen

\footnotetext{
${ }^{1}$ mayteotero@uma.es Profesora Área de Derecho Mercantil de la Universidad de Málaga.

${ }^{2}$ PAYNE y PERRET. Hotel franchising in Europe. En: Informe HVS London, 2014.
} 
español $^{3}$ se han desligado progresivamente de la propiedad y se han convertido en compañías especializadas en la gestión, aunque todavía hoy existe un alto porcentaje de hoteles en propiedad. La titularidad de algunos de los hoteles ha pasado a ostentarla otras empresas, generalmente, de inversión inmobiliaria y ajenas al sector turístico ${ }^{4}$.

\section{EL CONTRATO DE ARRENDAMIENTO DE EMPRESA HOTELERA}

El arrendamiento de empresa hotelera junto a la franquicia y la gestión, son los tres sistemas contractuales más utilizados en la explotación hotelera. Tras la gestión en propiedad, dentro de los tipos de explotación por terceros existentes, el mayoritariamente elegido por las cadenas españolas es el arrendamiento ${ }^{5}$.

Esta figura contractual es una de las más rígidas de las tres que hemos mencionado, ya que la suele utilizar aquel empresario hotelero más conservador que busca obtener una renta total o parcialmente fija sin asumir a penas riesgos y sin querer explotar directamente el establecimiento. En general, el propietario carece de conocimientos, no posee una marca notoria y le resulta más gravoso soportar la operativa diaria del establecimiento, es decir, las cadenas hoteleras poseen centrales de reserva propias, diseñan un marketing conjunto para todos los hoteles del grupo, entre otros instrumentos, que les permite generar economías de escala y, en consecuencia, una ventaja competitiva. Al titular del establecimiento también le interesa beneficiarse de la especial cualificación de la cadena hotelera, en este sentido depositará su confianza en ella para que explote el hotel diligentemente, pero evitando la responsabilidad que conlleva la explotación directa.

\footnotetext{
3 Una de las cadenas hoteleras españolas más importante a nivel internacional es Meliá International Hotels. Esta cadena optó por dejar atrás la propiedad y apostar por ser una gestora de hoteles al más puro estilo anglosajón. Asimismo, analizando los modelos utilizados por otras cadenas como AC Hotels, en sus comienzos, allá por los años sesenta, predomina la propiedad del inmueble hotelero. Este sistema de gestión directa se va modificando en las últimas décadas, incorporando nuevos modelos. En la actualidad cadenas como NH, Room Mate, AC by Marriott y Vincci amplían su cartera con nuevos hoteles en arrendamiento o gestión. Sin embargo, otros grupos hoteleros, como RIU e Iberostar mantienen su estrategia patrimonialista. Vid. FERNANDEZ BARCALA y GONZÁLEZ DÍAZ. Elección de la forma organizativa en las cadenas hoteleras: El caso de Sol Meliá. En: Papers de turismo. 2006, no. 39, pp. 2543.

${ }^{4}$ Debido a la necesidad de buscar nuevas vías de financiación como consecuencia de las distintas crisis económicas junto al apalancamiento y falta de liquidez que provoca la propiedad de los activos hoteleros, algunas cadenas hoteleras han decidido deshacerse de sus activos, vendiéndolos a grupos financieros, fondos de inversión o SOCIMIs, entre otros.

${ }^{5}$ Un reciente estudio muestra la evolución que han sufrido los hoteles según el modelo elegido para pertenecer a una cadena hotelera. En el periodo que va de 2010 a 2016, en España, se ha notado un leve incremento en el modelo de arrendamiento hotelero, pasando del 14,47\% al 15,8\%. Menos significativo es el porcentaje de implantación de la franquicia y la gestión, con un 3\% y un 7,8\% respectivamente. PASTOR y LOEDA. 200 Ediciones de Alimarket Hoteles y Restauración. En: Alimarket: Hoteles y Restauración, 2017, no. 200, pp. 6-11.
} 


\subsection{Régimen jurídico aplicable}

El contrato de arrendamiento de empresa posee una naturaleza mercantil. A pesar de la opinión de algunos ${ }^{6}$, que interpretan que no estamos ante un acto de comercio, nosotros entendemos que, al producirse la cesión de una empresa con determinadas características, como veremos en las siguientes líneas, sí se produce un acto de comercio, con independencia de la cualidad de comerciante del cedente. Además, este tipo de negocios jurídicos son interempresariales, generalmente ambas partes van a ser empresas, de manera que su mera presencia en el contrato junto a la naturaleza económica del mismo, hace presumir su mercantilidad ${ }^{7}$.

En la práctica, podemos identificar dos tipos de arrendamientos, el del inmueble con destino a hotel y el del negocio hotelero. El primero, no difiere apenas del mero arrendamiento urbano, por lo que le son de aplicación las normas contenidas en la Ley 29/1994, de 24 de noviembre, de Arrendamientos Urbanos, en concreto las correspondientes al arrendamiento para uso distinto al de vivienda ${ }^{8}$, por tener un destino orientado a la actividad empresarial ${ }^{9}$. Todo ello, sin perjuicio de lo que las partes pacten libremente. En este caso, el arrendador es titular del inmueble hotelero, pero no de la empresa, por lo que una vez formalizado el contrato, el arrendatario se subroga en los derechos y deberes que ostenta el arrendador, exclusivamente respecto del edificio.

Por tanto, en el arrendamiento de local de negocio se produce el uso y disfrute de una edificación para ejercer en ella una actividad empresarial. Mientras que en el de empresa, la finalidad es la continuación de la explotación de la empresa objeto de arrendamiento, entendiéndola como una compleja organización patrimonial productiva $^{10}$. En el primer caso estamos ante un elemento estático, como es el edificio

\footnotetext{
${ }^{6}$ Una línea doctrinal defiende la naturaleza mercantil del contrato por el mero hecho de que lo que se cede es una empresa, sin que exista un acto de comercio. MORALEJO IMBERNÓN, N. Contratos de cesión temporal de uso y disfrute. El arrendamiento de empresa. En BERCOVITZ RODRÍGUEZ-CANO, R. (Dir.) Tratado de Contratos, vol. II, Valencia: Tirant lo Blanch, 2013, p. 3049.

${ }^{7}$ PEINADO GRACIA, J.I. Las obligaciones mercantiles. En JIMÉNEZ SÁNCHEZ y DÍAZ MORENO (coords.) Derecho Mercantil, vol. V, Madrid: Marcial Pons, 2013, p. 64.

${ }^{8}$ Define el art. 3.2 LAU el arrendamiento para uso distinto del de vivienda como aquel que recae sobre una edificación cuyo destino sea ejercerse en la finca una actividad industrial, comercial, artesanal, profesional, recreativa, asistencial, cultural o docente, cualquiera que sean las personas que los celebren.

9 La distinción entre uno y otro tipo de arrendamiento ha suscitado debate en muchos ámbitos del Derecho debido a la confusión que se puede producir entre ambos. Así, por ejemplo, resultó en el marco de una SOCIMI que arrienda un hotel de su propiedad y se discute qué tipo de arrendamiento es en aras de la aplicación de un régimen fiscal determinado cuando, además del inmueble en el que radica el hotel, se ceden otros elementos necesarios para la explotación del mismo. Esta cuestión adquiere especial relevancia por estar la renta pactada sujeta a un canon fijo y una cantidad variable directamente relacionada con el beneficio bruto de explotación del hotel. La Dirección General de Tributos entendió que la explotación del hotel corría por cuenta y riesgo del arrendatario, por lo que dicha circunstancia podría entenderse como un dato clave para permitir la aplicación del régimen. Vid. SERRANO DE HARO, FERNÁNDEZ y CHANCE. Nuevo régimen de las Sociedades Anónimas Cotizadas de Inversión en el Mercado Inmobiliario (SOCIMIs): cuestiones prácticas a tener en cuenta en la implementación del régimen. En: AA.VV., 2014 Práctica Fiscal para Abogados, Madrid: Dykinson, 2014.

10 Diferenciación expuesta por FONT GALÁN y PAGADOR LÓPEZ. La empresa como objeto de negocios jurídicos. En: JIMÉNEZ SÁNCHEZ y DÍAZ MORENO (coords.) Derecho Mercantil, vol. I, Madrid: Marcial Pons, 2013,p. 218.
} 
hotelero, y en el segundo, ante un elemento dinámico ${ }^{11}$ como es la empresa hotelera. En el tráfico jurídico es necesario identificar el tipo de contrato suscrito, en aras de conocer la normativa aplicable y la posición jurídica que ostenta cada una de las partes. Esto no resulta siempre fácil, bien porque las partes no lo hayan definido expresamente o bien porque, de los compromisos que asumen no se desprenda con suficiente claridad el tipo de negocio.

La distinción entre ambos contratos ha sido abordada en sede judicial. La doctrina del Tribunal Supremo ${ }^{12}$ ha señalado que mientras en el de local se cede el elemento inmobiliario, es decir, un espacio construido y apto para que en él se explote el negocio, en el de empresa el objeto contractual está determinado por una doble composición integradora, por un lado el local, como soporte material y, por otro, el negocio o empresa instalada y que se desarrolla en el mismo, con los elementos necesarios para su explotación, conformando un todo patrimonial. No obstante, lo que nos indican nuestros tribunales es que habrá que interpretar cada contrato, analizando su contenido y los términos en que se haya redactado.

Sin embargo, podemos identificar algunos rasgos característicos que nos ayudarán a calificar el contrato como de arrendamiento de empresa. Por un lado, nos encontraremos ante negocios jurídicos de mayor duración, alcanzando en el caso de la empresa hotelera incluso los 25 años ${ }^{13}$. También cobra relevancia la determinación de la remuneración que suele ser variable o fijo más variable. Este pacto muestra el interés y la participación del transmitente en la viabilidad y éxito de la empresa. Por último, la limitación de alteración de las características del negocio, estando condicionado por los elementos que formen parte de la empresa, sin poder operar en ningún caso un cambio de negocio. Todo ello sin perjuicio de otras características ${ }^{14}$.

Algunos autores ${ }^{15}$ consideran que determinados contratos turísticos, como es el caso del alojamiento o el catering, por ejemplo, son verdaderos arrendamientos de

\footnotetext{
11 Recordamos, tal y como históricamente se ha estudiado, que el objeto de este tipo de contrato es tanto una cosa productiva y dinámica, como específica MOTOS GUIARO, M., «El arrendamiento de empresa», en AA.VV., Estudios jurídicos en homenaje a Joaquín Garrigues, Tecnos, Madrid, 1971, p. 482.

12 En este sentido se pronuncian las sentencias del Tribunal Supremo (Sala $1^{\text {a }}$ ) de 21 de diciembre de 1990, (Sala $1^{\text {a }}$ ) de 20 de septiembre de 1991, (Sala $1^{\text {a }}$ ) de 25 de mayo de 1992, (Sala $1^{\text {a }}$ ) 379/1993, de 17 de abril de 1993, (Sala 1ª) 552/1998, de 8 de junio de 1998, (Sala 1ª)137/2000, de 21 de febrero de 2000.

${ }_{13}$ El tiempo es un rasgo diferenciador entre ambos tipos de arrendamientos pero es importante tener en cuenta que en el caso de los establecimientos hoteleros pueden existir excepciones a esta regla. Ya que existen contratos de arrendamiento de local con una duración mayor que, incluso alcanzan los 10 y 15 años. Esto es porque generalmente en el arredramiento del edificio hotelero, el arrendatario, deberá realizar reformas e inversiones para adaptar el establecimiento a su imagen y a los servicios que presta. Si en tales casos se suscribiera un contrato por un tiempo inferior al comentado no produciría la rentabilidad suficiente al arrendatario ni compensaría la inversión realizada.

${ }^{14}$ Estas características, en contrario, han sido las utilizadas por la sentencia de la Audiencia Provincial de Madrid (Sección 10 ) 100/2010, de 17 de febrero de 2010, en un procedimiento de expiración del término de arrendamiento de un local destinado a gimnasio ubicado en las instalaciones de un establecimiento hotelero. Resultan bastante esclarecedores los argumentos que esgrimen tanto la parte apelante como la Audiencia Provincial, para justificar qué presupuestos operan para distinguir si estamos ante uno u otro tipo de arrendamiento. Especialmente ilustrativa es la sentencia de la Audiencia Provincial de Málaga (Sección 6), 230/2017 de 12 de marzo de 2017 al examinar los elementos más importantes del arrendamiento de empresa hotelera, confrontando este tipo contractual con el de arrendamiento de local ante el supuesto de resolución contractual de un arrendamiento hotelero y la reclamación de cantidad por daños y perjuicios por incumplimiento.

15 PÉREZ-SERRABONA GONÁLEZ, J. Arrendamientos mercantiles. En JIMÉNEZSÁNCHEZ y DÍAZ MORENO (coords.) Derecho Mercantil, vol. V, Madrid: Marcial Pons, 2013, p. 269.
} 
empresa mercantil. En estos casos, según nuestro punto de vista, estaremos ante un mero arrendamiento de servicios o externalización, totalmente diferenciado de la explotación hotelera y sin ser arrendamientos de empresa o de cosa productiva en sentido estricto.

La relevancia radica en que en los supuestos de explotación de un hotel, el arrendamiento va dirigido al alquiler de la empresa hotelera. La doctrina ${ }^{16}$ define el contrato de arrendamiento de empresa o de industria ${ }^{17}$ como aquel negocio jurídico en virtud del cual se opera, por precio cierto y tiempo determinado, la cesión unitaria de un conjunto organizado de elementos materiales e inmateriales afectos a una misma finalidad económica de producción y/o intermediación de bienes y servicios dentro del mercado.

Se trata de un contrato atípico, que durante la pasada crisis económica no ha sido de los más corrientes en el sector turístico, pero en los últimos años algunas cadenas hoteleras han retomado la utilización de esta figura. Generalmente se convierte en un modelo de gestión por el que a cambio de una cantidad económica acordada por las partes, se establece un régimen conjunto de alquiler y de explotación del hotel, normalmente de larga duración.

Al no existir una regulación más precisa del ámbito de aplicación, del contenido, de las obligaciones de las partes y de la extinción del contrato, dificulta aislarlo de otros contratos habituales en el ámbito interempresarial turístico. Dado que la relación jurídica concreta una separación entre la titularidad de la empresa y la explotación de la misma, puede confundirse con el contrato de gestión ${ }^{18}$. Si profundizamos en ambas relaciones, veremos una diferencia esencial en estos dos contratos. En el caso del arrendamiento se produce una separación entre la titularidad de la empresa y la explotación de la misma, la explotación pasa a desempeñarla el arrendatario. En el caso de la gestión no existe ningún tipo de traslado del negocio ni de la posesión del inmueble, sino que el gestor se ciñe a cumplir con la encomienda del titular de administrar un negocio ajeno.

En este punto cabría diferenciarlo además del contrato de agencia debido a su cualidad común de ser un negocio jurídico de gestión de intereses ajenos ${ }^{19}$. A pesar de este hecho, la empresa explotadora tanto en el contrato de gestión hotelera como en el arrendamiento de empresa tiene un especial interés en el devenir del negocio, no exclusivamente económico. Incluso la empresa explotadora aporta mucho más que su mera cooperación, así ocurre con la licencia de marca, la transmisión del knowhow o la formación del personal en el contrato de gestión hotelera. Además, la empresa

\footnotetext{
${ }^{16}$ COSTAS RODAL, L. Contratos de cesión temporal de uso y disfrute. En BERCOVITZ RODRÍGUEZCANO, R. (Dir.) Tratado de Contratos, vol. II, Valencia: Tirant lo Blanch, 2013, p. 3047.

17 También denominado arrendamiento de establecimiento mercantil vid. ROJO, A. El establecimiento mercantil. En MENÉNDEZ Y ROJO (dirs.) Lecciones de Derecho Mercantil, vol. I, Navarra: ThomsonCivitas, 2016, p. 113.

18 Ninguna afinidad existe entre el arrendamiento de empresa y el contrato de gestión. No obstante, sí debemos mencionar que los contratos de gestión que hoy en día formalizan grandes cadenas hoteleras como son HILTON o Inter Continental, surgieron tras los cambios producidos en contratos previos de arrendamiento de inmuebles para uso hotelero o de empresa hotelera. Los primeros contratos de gestión de estas cadenas tenían un contenido similar a los de arrendamiento del inmueble, incluso hoy en día todavía se mantiene alguna cláusula. Información más detallada puede obtenerse en EVANOFF, M. The international hotel management agreement: Origins, evolution, and status. En: Cornell Hospitality Report, 2016, no. 11, pp. 3-15.

${ }^{19}$ ALONSO SOTO y SÁNCHEZ ANDRÉS. Los contratos de colaboración. En MENÉNDEZ Y ROJO (dirs.) Lecciones de Derecho Mercantil, vol. II, Cizur Menor: Thomson-Civitas, 2016, pp. 97-114.
} 
encargada de la gestión no es habitual que explote aisladamente un único hotel, incluso puede poseer otros establecimientos en propiedad y próximos al que gestiona o arrienda, cuestión que entra en conflicto directo con el art. 7LCA, al impedir al agente realizar por cuenta propia o ajena cualquier actividad profesional relacionada con bienes y servicios que sean de igual o análoga naturaleza y concurrencia o competitivos con aquellos cuyas contrataciones hubiera obligado a promover ${ }^{20}$.

A estas diferencias, debemos añadir otras que nacen al amparo de las relaciones jurídicas incluidas en los contratos de explotación hotelera, sin responder con exactitud a lo establecido en la formulación común del contrato de agencia ${ }^{21}$. Una diferencia que distancia al contrato de agencia y gestión es la intensa relación jurídica que nace entre las partes. En la gestión no existe una relación de subordinación como en la agencia, e incluso podríamos decir que, en muchas ocasiones, entidad gestora ocupa una posición más hegemónica que la del titular. Por lo que, generalmente las partes actúan en un plano de igualdad en la gestión del negocio ajeno y el gestor no recibe apenas injerencias ni el empresario interviene directamente en las labores del gestor, aunque la cadena hotelera debe reconocerle capacidad de control y decisión, además de informarle periódicamente de su gestión. A ello cabe añadir que el cometido del gestor es mucho más amplio y de mayor envergadura que los negocios vinculados a la agencia mercantil ${ }^{22}$.Este examen que acabamos de realizar nos resulta de utilidad para comprobar la falta de afinidad también entre el arrendamiento de empresa y el contrato de agencia. En puridad, el empresario arrendatario nunca va a actuar por cuenta del titular de la empresa arrendada, éste último tiene que dejarle hacer.

Siguiendo con las diferencias entre el contrato de gestión y el que es objeto de estudio, debemos destacar que el arrendatario usa y disfruta la empresa exclusivamente para su propio beneficio y el gestor hotelero explota un negocio ajeno, en beneficio del titular. Además, como acabamos de comentar, el titular del hotel puede ejercer cierto control sobre la gestión, según lo pactado, en el arrendamiento de empresa no. A pesar de que en ambos negocios la remuneración venga pactada según un porcentaje de los beneficios obtenidos, los destinatarios son distintos. En el contrato de gestión el titular de la empresa obtiene la totalidad de los beneficios detrayendo el porcentaje que le corresponda en concepto de honorarios a la cadena hotelera gestora, mientras que en el caso del arrendamiento es a la inversa, los beneficios los recibe el arrendatario y un porcentaje de éstos, el arrendador.

Por último, una diferencia esencial en el contrato de gestión hotelera es la actuación del gestor en nombre del titular de la empresa ${ }^{23}$, a través de un poder de representación otorgado al efecto. El titular se compromete a otorgar los poderes generales oportunos para que la cadena hotelera actúe en su nombre en todos los ámbitos propios de la gestión ordinaria del hotel. Esta situación no se da en el

\footnotetext{
20 Para un estudio pormenorizado vid. MARTÍNEZ SANZ, PALAU RAMÍREZ y MONTEAGUDO MONEDERO. Comentario a la Ley sobre el Contrato de Agencia, Madrid: Civitas,2000.

${ }^{21}$ ALCOVER GARAU, G. Aproximación al régimen jurídico del contrato de gestión hotelera. En: Revista de Derecho Mercantil, 2000, no. 237, p. 1006.

${ }^{22}$ El contrato de agencia, con frecuencia, se utiliza para externalizar parte de los servicios de una empresa, como puede ser el departamento comercial. Sin embargo en la gestión, la encomienda es sobre la totalidad del negocio hotelero. Dentro del propio negocio hotelero puede la cadena gestora decidir externalizar o encomendar a terceros determinadas tareas valiéndose de la figura jurídica del contrato de agencia. Un claro ejemplo lo encontramos en los contratos que se suscriben con las agencias de viajes.

${ }^{23}$ Las obligaciones del gestor en el contrato de gestión hotelera tienen un carácter mucho más amplio. ÍNIGUEZ ORTEGA, P. El contrato de gestión hotelera, Valencia: Tirant lo Blanch, 2015, p. 58.
} 
arrendamiento, dado que la cadena hotelera como arrendataria actúa y se obliga en nombre propio.

En sintonía con estas diferencias expuestas, el traslado de la posesión es una característica que nos sirve también para diferenciar el contrato que estudiamos de la franquicia. La franquicia pertenece a la clase de contratos que denominamos de distribución, entendiéndola como una figura que contribuye a la expansión de un modelo de empresa, sin que en ningún momento se ceda la organización empresarial ${ }^{24}$.

La falta de disciplina jurídica del arrendamiento de empresa motiva también que debamos atender a la autonomía de la voluntad de las partes. Habrá que someter el contenido del negocio jurídico, cuando sea compatible, a las normas que en materia de arrendamiento de cosas dispone el CC en los artículos 1542 y ss. $^{25}$, siempre bajo la premisa de que estas normas civiles se convierten en insuficientes y con una escasa adecuación al supuesto que estudiamos ${ }^{26}$. No obstante, debemos destacar los pasos que se han dado en el Anteproyecto de Ley de Código de Comercio, regulando por primera vez el arrendamiento de empresa conjuntamente con el usufructo. Dentro de los seis artículos dedicados a esta figura debemos prestar atención sobre la aplicación de las normas de la compraventa en la entrega de la empresa, así como la exigencia de diligencia en la gestión de la empresa, asumiendo sus pérdidas y la restitución de la misma a la extinción del contrato, operando las compensaciones económicas pertinentes. Estas normas proyectadas se hacen eco de las principales características de este contrato, como veremos a continuación.

\subsection{Contenido y características de la relación contractual}

El contrato de arrendamiento de empresa hotelera es un contrato consensual. Existe y se perfecciona por el consentimiento de ambas partes. Salvo pacto en contrario, estamos ante un negocio jurídico eminentemente oneroso, convirtiéndose, en este caso, la retribución en uno de los elementos clave en los tratos preliminares a la celebración del contrato y durante la vida del mismo. Estamos, además, ante un negocio de tracto sucesivo, que perdurará en el tiempo, generando una relación duradera entre las partes. Por último, rige el principio de libertad de forma, aunque lo habitual, dada la complejidad del contenido será la forma escrita e incluso cualquier comunicación entre las partes cumplirá dicha solemnidad.

Respecto a los elementos personales, cabe decir que de una parte nos encontramos con el titular del negocio hotelero denominado $\operatorname{arrendador}^{27} \mathrm{y}$, de otro

\footnotetext{
${ }^{24}$ MORALEJO IMBERNÓN, N. Contratos de cesión temporal de uso y disfrute..., op. cit., p. 3054.

${ }^{25}$ El arrendamiento de empresa se ha excluido expresamente de la legislación sobre arrendamientos urbanos, a pesar de conservar rasgos comunes con este. El problema radica en el contenido propio del contrato que difiere en muchos casos del arrendamiento de cosa. MESA MARRERO y LÓPEZ LÓPEZ. El arrendamiento de empresa. En YZQUIERDO TOSLADA, M. (Dir.) Contratos: civiles, mercantiles, públicos, laborales e internacionales, con sus implicaciones tributarias, vol. III, Navarra: AranzadiThomson Reuters, 2014, p. 533.

${ }^{26}$ A pesar de su aplicación por la vía de la analogía, no regulan el arrendamiento de empresa, ya que éste, por su propia naturaleza compuesta por un conjunto de cosas y de servicios productivos y de carácter especial, no puede entenderse incluido ni en el arrendamiento de obra, ni en el de servicios ni en el de fincas rústicas y urbanas.

${ }^{27}$ En nuestro estudio vamos a partir de que tanto la titularidad del inmueble como la del negocio hotelero recaen sobre la misma persona. Existen casos complejos en los que el titular del inmueble es una persona distinta al titular del negocio hotelero y entre ellos formalizan un contrato de arrendamiento de local de
} 
lado, la empresa que lo explotará, el arrendatario, que en la mayoría de los casos coincidirá con una cadena hotelera. Estos sujetos deberán cumplir con las normas comunes para poder obligarse, tener capacidad jurídica y poder realizar actos de comercio. El resto de elementos merecen un estudio más detenido.

Teniendo en cuenta todo lo expuesto, hemos considerado relevante centrarnos en algunos aspectos del contenido del contrato que poseen mayor trascendencia en la especialidad de empresa hotelera. De esta manera, destacamos la obligación que ostenta el arrendador de garantizar el goce pacífico del negocio hotelero, la determinación del precio, la duración del contrato, así como su extinción y régimen de responsabilidad.

\subsubsection{Goce pacífico del negocio hotelero ${ }^{28}$}

El goce pacífico del negocio queda, en gran parte, supeditado al contenido obligacional del contrato. Los deberes de colaboración que se plasman en el arrendamiento de empresa, son el camino por el que discurrirá la ejecución del contrato. El arrendador está obligado a colaborar con el arrendatario, garantizando la verdadera entrega del negocio desde todos los puntos de vista. Está obligado a poner en conocimiento todos aquellos aspectos que estén relacionados con la explotación de la empresa, desde el knowhow hasta los documentos contables ${ }^{29}$. Una vez extinguido el contrato, estas obligaciones revierten en el arrendatario en el momento de la entrega de la empresa.

En este tipo contractual el arrendatario va a recibir el inmueble, como local de negocio y el propio negocio, que deberá estar ya en funcionamiento o requerir dar los primeros pasos, generalmente administrativos, para iniciar la explotación del hotel. En nuestra opinión, en contra de lo que defiende la doctrina ${ }^{30}$ y parte de nuestra jurisprudencia $^{31}$, entendemos que existe un contrato de arrendamiento de empresa,

negocio. A su vez, el titular del negocio hotelero formalizara otro contrato con un tercero para el arrendamiento de la industria.

${ }^{28}$ Entiéndase que aplicamos las características contenidas en el artículo 1543 CC sobre el arrendamiento de cosa, al negocio hotelero. En este sentido, el precepto señala que: en el arrendamiento de cosas, una de las partes se obliga a dar a la otra el goce o uso de una cosa por tiempo determinado y precio cierto.

${ }^{29}$ VARA DE PAZ, N. El arrendamiento de empresa. En: Cuadernos de derecho y comercio, 1988, no. 4, p. 62 .

${ }^{30}$ La doctrina entiende que debe ser susceptible de inmediata explotación después del cambio de titular o que esté pendiente de simples formalidades administrativas. En consecuencia, debe haber funcionado previamente aunque transitoriamente haya cesado en su actuación. Siendo, además, la finalidad del contrato la de continuar la explotación del arrendador y no instalar ex novo la propia del arrendatario. GARCÍA CANTERO, G. Arrendamiento de empresa: aspectos civiles y mercantiles. En: Actualidad laboral, 1996, no. 1, pp. 277-295.

31 La jurisprudencia ha destacado como características clave del arrendamiento de empresa que la industria o unidad de explotación económica exista a la firma del contrato. No admitiendo como tal la mera mención en el mismo de la obligación de destino del local a una industria determinada. Así se pronuncia la Sentencia de la Audiencia Provincial de Las Palmas(Sección 5a) 554/2012, de 30 de noviembre de 2012, en el procedimiento seguido por el Grupo turístico Barceló S.L. y Eurothermes España S.L., la primera arrienda un local en construcción dentro de su complejo hotelero para que la segunda lo explote como SPA.

Debemos añadir que en la práctica, existen casos en los que se formalizan contratos de arrendamiento de empresa hotelera con el hotel proyectado sin finalizar las obras, condicionando los contratos a su completa terminación. En tales casos, será el arrendatario el primero en explotar el hotel. Un ejemplo, aunque el litigio verse sobre otras cuestiones, es la Sentencia del Tribunal Supremo (Sala 1ª) 790/2013, de 27 de diciembre de 2013, cuyo supuesto de hecho está relacionado con la titularidad de un arrendamiento financiero para la construcción de un hotel por parte de la empresa Covas Arnau S.A., que a su vez y 
aunque esta no haya prestado ningún servicio de alojamiento, cuando la intención de las partes sea la transmisión de una empresa y no exclusivamente la de un local de negocio. Siempre que, además, la empresa constituya una verdadera unidad productiva con todos sus elementos. La clave radicará en las obligaciones recíprocas que acuerden las partes tanto durante la vigencia del contrato como en el momento de la restitución de la empresa.

Junto a la cesión del inmueble y de las zonas aledañas, deben entenderse incluidos también los bienes afectos al mismo ${ }^{32}$ y necesarios para el desempeño y continuación del negocio hotelero. Normalmente las partes realizan un inventario de los bienes $^{33}$ que se ceden en el arrendamiento. Se trata de un documento anexado al contrato principal y en el que aparecen rigurosamente enumerados cada uno de los enseres que existen en el hotel en el momento de la firma del contrato, en cada extremo de las instalaciones, tanto en las propias habitaciones como en las zonas comunes ${ }^{34}$. En los casos en que el inventario no se realice, nuestra doctrina y jurisprudencia ${ }^{35}$ ha

previo a la finalización del inmueble, firma un contrato de arrendamiento con la cadena hotelera Sol Meliá.

32 Hay que tener en cuenta, que según lo establecido en el art. $334 \mathrm{CC}$, habrá que considerar como inmuebles aquellos bienes muebles que estén unidos a un bien inmueble de manera fija, de forma que no puedan separarse de aquél sin quebrantamiento de la materia o deterioro del objeto que junto a él componen. HERNANDO CEBRIÁ, L. La transmisión de la empresa a través de distintos contratos. En: Revista de Derecho Mercantil, 2001, no. 242, p. 1898, parte el autor de la concepción de los bienes inmuebles por incorporación que realiza la sentencia del Tribunal Supremo de 18 de marzo de 1961, ante la controversia surgida por la terminación de un contrato de arrendamiento de local, declarando que "aun cuando los lavabos, bañeras, radiadores, tuberías exteriores, sean aisladamente muebles, de por sí desde el momento de que de manera fija se inmovilizan por unión o agregación a un inmueble, pierden su naturaleza peculiar y adquieren la consideración jurídica de bienes inmuebles por incorporación al quedar unidor a él de manera duradera y precisa".

${ }^{33}$ Es importante destacar que el recurso al inventario de bienes afectos al establecimiento y, por tanto, a la actividad económica, es una herramienta que utiliza también el arrendamiento de local de negocio. En nuestra investigación nos consta que en este tipo de contratos cuyo objeto es el alquiler del inmueble hotelero, destaca también la inclusión de un documento que acredita haber realizado un inventario previo junto al soporte gráfico pertinente. Por tanto, no es suficiente la cesión de enseres contabilizados en un inventario para qué el arrendamiento se configure como de empresa.

${ }^{34}$ Los términos en que se redactan estas cláusulas que generalmente remiten al listado anexado, incluyen la obligación de reparación o reposición a la parte arrendataria del deterioro o menoscabo de los bienes producidos por un mal uso, sin perjuicio del derecho de la parte arrendadora a ejercitar las acciones oportunas para su reparación o reposición.

35 Podemos equiparar, como se viene haciendo, el arrendamiento de empresa con el de sucesión de empresa, sobre todo en los supuestos de cesión de los bienes que componen la unidad de explotación. De esta manera, creemos conveniente traer a nuestro estudio el caso analizado por VILATA MENADAS, S. El tratamiento de la sucesión empresarial en el traspaso de unidades empresariales: una visión jurisprudencial. En: Revista de Derecho Concursal y Paraconcursal, 2008, no. 8, pp. 491-508: El Tribunal Supremo sostenía que el supuesto de hecho de la sucesión de empresa estaba integrado por dos requisitos esenciales, a saber el cambio de titularidad y que los elementos patrimoniales cedidos constituyan una unidad de producción susceptible de explotación o gestión separada, de lo que se deriva que no basta la simple transmisión de bienes. Se requería la cesión de elementos patrimoniales significativos e indispensables para la actividad, que hicieran posible que la empresa siguiera funcionando tras la transmisión.

La jurisprudencia ha venido argumentando que la entrega de determinadas instalaciones no es suficiente para calificar el contrato de arrendamiento de industria sino meramente de arrendamiento de local de negocio con instalaciones, pues, para la existencia de arrendamiento de industria es ineludible la preexistencia de una actividad negocial que se continúe por el arrendatario. Es decir, que verdaderamente esos bienes constituyan una unidad empresarial que ofrezca un resultado económico. En este sentido pueden consultarse las Sentencias del Tribunal Supremo (Sala $1^{\text {a }}$ ) 84/1985, de 8 de febrero de 1985, (Sala $1^{\text {a) }}$ 48/1986, de 31 de enero de 1986, (Sala 1 a) de 10 de noviembre de 1986 y (Sala $1^{\text {a }}$ ) de 24 de febrero de 1987. Así como jurisprudencia menor reciente: Sentencia de la Audiencia Provincial de Madrid (Sección 
entendido que se comprenden cedidos todos aquellos bienes esenciales que formen la unidad básica de explotación y sin los cuales el funcionamiento de la empresa sería imposible, atendiendo siempre al tipo de industria en el que nos hallemos ${ }^{36}$.

Asimismo, dentro del goce del negocio debe incluirse el buen uso del mismo, el reparto de obligaciones y voluntades para realizar mejoras, obras de conservación y remodelación, reparaciones y reposición, entre otras y según el caso concreto. En este ámbito el $\mathrm{CC}$ ha establecido algunas directrices para el arrendamiento de cosa que deberán ser aplicadas de manera supletoria, siempre y cuando no existan pactos al respecto. El reparto residual de obligaciones viene regulado en los artículos 1554 para el arrendador y $1555 \mathrm{CC}$ respecto del arrendatario. De las previsiones contenidas en ambos preceptos debemos destacar la obligación que ostenta el arrendador de hacer todas las reparaciones necesarias a fin de conservar la cosa en estado de servir para el uso a que ha sido destinada. Del mismo modo, es obligación del arrendatario, usar la cosa arrendada como un diligente padre de familia. En nuestro caso la cosa sería el negocio y la diligencia debe alcanzar a un buen comerciante. Ambos preceptos debemos ponerlos en relación con el art. 1553 del mismo texto legal que remite, en los supuestos de saneamiento de la cosa, a las disposiciones contenidas en materia de compraventa. De esta manera, al igual que ha confirmado algún autor ${ }^{37}$, al arrendamiento de empresa le son de aplicación mutatis mutandis, lo dicho respecto a la compraventa de empresa. Tomando en consideración esta proximidad contractual y dada la especialidad de la figura, habrá que concretar a qué se refiere cada una de las obligaciones antes mencionadas.

La jurisprudencia ${ }^{38}$ se ha afanado en aclarar que considera intrascendente la introducción de mejoras en las instalaciones por parte del arrendatario, puesto que ello no supone una actividad creadora, sino mejoras sobre la actividad ya creada. Siguiendo la finalidad de cumplir con esta obligación, es habitual introducir una cláusula en el contrato que obligue al arrendador a hacer las reparaciones necesarias para el buen uso del negocio. De esta manera quedan reflejadas las obras que se compromete a acometer para dotar a las dependencias hoteleras de las debidas condiciones, consiguiendo que sirvan al fin para el que fueron arrendadas, que no es otro que prestar el servicio de alojamiento. En el marco de esta obligación es decisivo conocer qué debe entenderse por reformas u obras necesarias. Éstas, tal y como expone la jurisprudencia, no englobaran la realización de mejoras para el buen uso del negocio, sino las referentes al simple uso de este ${ }^{39}$.

En consecuencia, si es deseo del arrendatario introducir mejoras, deberá realizarlas él mismo como iniciativa que surge a raíz de su gestión porque considere que tienen incidencia directa en el buen funcionamiento y en los resultados económicos del negocio. En ocasiones, y según lo pactado, necesitará la autorización previa del arrendador.

El goce pacífico de la cosa incluye además que el titular de la explotación ostente los permisos y licencias, así como garantice estar al día con cualquier trámite

\footnotetext{
$10^{\mathrm{a}}$ ), 100/2010 de 17 de febrero de 2010.

${ }^{36}$ MORALEJO IMBERNÓN, N. El arrendamiento de empresa. Pamplona: Aranzadi, 2004, p. 139.

37 Por todos, vid. PAGADOR LÓPEZ, J. La empresa. En: JIMÉNEZ SÁNCHEZ, G. (coord.) Nociones de Derecho Mercantil, Madrid: Marcial Pons, 2016, p. 23.

38 Vid. sentencia de la Audiencia Provincial de Les Illes Balears (Sección 4a) 93/2009, de 17de marzo de 2009, F.D. 6

39 Vid. sentencia Audiencia Provincial de Lugo (Sección 1 ${ }^{\text {a) }}$ 604/2007, de 14 de septiembre de2007, D. 2.
} 
administrativo legalmente exigido para que el arrendatario pueda explotar sin injerencias de terceros el establecimiento hotelero. La obligación de obtención y posesión de licencia administrativa, se haya requerido o no expresamente por las partes, ha sido considerada por nuestra jurisprudencia ${ }^{40}$ un elemento esencial para la explotación de la industria hotelera objeto del contrato cuyo cumplimiento atañe a ambas partes, aunque se le reconoce una mayor diligencia para su obtención a la arrendataria, existiendo un deber de colaboración de la arrendadora. Dicha obligación se ha considerado que está relacionada con el goce pacífico de la cosa y con el objetivo de evitar que existan vicios que dificulten o impidan ese goce.

Como podemos observar el arrendatario debe ser muy cauto en las negociaciones del contrato de arrendamiento, ya que tiene que ser consciente de que tanto el riesgo como la ventura del negocio recaen sobre su figura ${ }^{41}$, sólo con los límites de la restitución que hemos mencionado. De ahí, también la ausencia de autoridad del arrendador sobre el devenir y las decisiones del negocio.

\subsubsection{Cesión de los signos distintivos}

Junto a la transmisión del inmueble nos encontramos con la traditio de la marca. Tanto la marca como cualquier otro signo distintivo son elementos intrínsecos al negocio hotelero, sin embargo, con frecuencia su cesión queda al arbitrio del titular. Generalmente, existen casos en los que el arrendador posee una marca propia y las partes acuerdan incorporar esa marca ${ }^{42}$, dado que se considera un bien más a transmitir junto con el resto del negocio. Puede que se haga mención expresa en el contrato o bien, siendo plenamente válida, se entienda cedida tras conversaciones mantenidas con el

\footnotetext{
40 Vid. sentencia de la Audiencia Provincial de Madrid (Sección 14 ${ }^{\text {a }}$ ) 85/2016, de 17 de marzo de 2016, respecto del procedimiento seguido entre Hostelería y Catering, S.L. como arrendadora y Servicios y Estudios para la Navegación Aérea y la Seguridad Aeronáutica S.A. como arrendataria. Ambas habían suscrito un contrato de arrendamiento de empresa sobre un establecimiento hotelero desde 1992, el cual había sufrido distintas novaciones y había sido subarrendado. La controversia nació en relación a la falta de realización de las gestiones necesarias ante los organismos que se requerían, con el fin de obtener las licencias exigidas para la explotación de la industria hotelera.

${ }^{41}$ Plantea PÉREZ MORIONES, A. El contrato de gestión hotelera, Valencia: Tirant lo Blanch, 1998, p. 210, la posibilidad de que la cadena arrendataria estipule un contrato de gestión hotelera, de modo que la dirección del negocio objeto del contrato de arrendamiento sea asumida por otra cadena, sin necesidad de recabar el consentimiento del arrendador. La autora cuestiona tal posibilidad, a menos que exista un consentimiento expreso por parte del arrendador, pues es intención de éste atribuir la gestión a la arrendadora por su especialización y experiencia y por los medios que esta dispone y no a otra gestora ajena.

${ }^{42}$ La transmisión de la empresa conlleva igualmente la de sus marcas y nombre comercial a menos que se hubiera acordado otra cosa o pudiera deducirse una voluntad contraria de las circunstancias del caso. También es posible facultar expresamente al arrendatario en los casos en que quiera cambiar el nombre comercial durante la vigencia del arrendamiento de empresa. Supuestos similares resuelven las sentencias del Tribunal Supremo de 7 de marzo y de 20 de septiembre de 1991. Vid. MORALEJO IMBERNÓN, N. El arrendamiento de empresa, op.cit., p. 156.

Así también BROSETA PONT, M. La transmisión de la empresa: Compraventa y arrendamiento. En: Revista de Derecho Mercantil, 1968, no. 107, pp. 59-106, al asimilar el contrato de arrendamiento de empresa con el de transmisión de empresa o compraventa, podemos entender que la marcase "cede" como un bien esencial más integrante del negocio hotelero y, por tanto, otorgando al cedente plenos derechos de explotación y uso de la marca en el tráfico económico. En la mayoría de los casos se ha identificado el negocio jurídico de la cesión de marca con el de la compraventa, llegando a hablarse de transmisión de los derechos de marca en lugar de cesión. Nosotros, como bien ha reconocido la doctrina, abogamos porque la marca pueda cederse por actos inter vivos en los supuestos de arrendamiento de empresa.
} 
arrendatario o cuando, prestando atención a sus actos, no pueda desprenderse fehacientemente una manifestación contraria a su uso.

En ocasiones, es posible que, por diversas razones, el arrendador no posea una marca en el mercado con suficiente notoriedad, convirtiéndose éste en uno de los motivos que originan la búsqueda de una cadena hotelera para arrendar el hotel. O bien el negocio aún no haya sido explotado, por ello el titular del mismo procurará que la arrendataria ceda el uso de su marca para incorporarla al establecimiento. En este caso, no estaremos ante una cesión de uso como ocurría en el caso de la marca de la que era titularidad el arrendador, sino más bien se tratará de una autorización por parte del arrendador para que el establecimiento asuma y se realicen las reformas o se modifiquen los elementos pertinentes, con la finalidad de adaptarlo a la imagen y denominación de la cadena hotelera arrendataria. Entendemos que no opera la licencia de marca dado que quien va a efectuar la gestión y se obliga en nombre propio es la cadena hotelera, titular de la marca. Sería un sinsentido que tuviese que licenciarse a sí misma, a menos que no fuese la titular.

Nuestra legislación marcárea, tanto nacional como comunitaria, consagra el principio de libertad de cesión, siempre que exista una transmisión de empresa y que ésta se realice en su totalidad ${ }^{43}$, salvo que la misma pueda inducir a error a terceros ${ }^{44} \mathrm{O}$ exista una prohibición expresa ${ }^{45}$. Esta libertad permite reflejar en el contrato de explotación cómo se va a producir la cesión y bajo qué condiciones o directrices se permite, así como, según el caso, la autorización para que el arrendatario utilice su propia marca a lo largo del arrendamiento.

La finalización del negocio produce importantes efectos sobre los signos distintivos, pudiendo plantear problemas ya que llegado el término ${ }^{46}$ deberá devolverse

\footnotetext{
${ }^{43}$ En este sentido, resulta relevante recordar el asunto del Hotel Ritz, en el que el Tribunal Supremo dictó sentencia de 14 de octubre de 1993, en la que declaraba que la ejecución de una hipoteca que recae sobre el edificio que acogía el indicado hotel y la consiguiente transmisión de la propiedad del mismo, en modo alguno puede interpretarse como cesión de empresa que justificase un cambio de titularidad del rótulo "Hotel Ritz". GONZÁLEZ-BUENO, C. Artículo 47. Transmisión de la marca. En GONZÁLEZ-BUENO, C. (coord.) Comentarios a la Ley y Reglamento de Marcas, Madrid: Civitas, 2003, p. 477. Si utilizamos este ejemplo, vemos como al no existir transmisión de empresa no se transmite la marca, exclusivamente se adquiere el inmueble, con independencia de que su destino fuese el de uso hotelero. El Tribunal quiso poner de manifiesto que la hipoteca constituida por el dueño del establecimiento será independiente de la que pudiera constituir sobre el inmueble de su propiedad, es decir, al titular se le ofrecen dos posibilidades de garantía, la hipoteca inmobiliaria sobre la finca exclusivamente o la mobiliaria sobre el establecimiento. En el supuesto de la sentencia sólo se hipoteca la primera.

Otro asunto que tiene como protagonista a la mercantil Hotel Ritz Madrid, S.A., es la sentencia de la Audiencia Provincial de Madrid (Sección 28 ), 203/2014 de 23 de junio de2013, que discute la aportación del derecho a usar el signo distintivo "Hotel Ritz" a Hotel Ritz de Barcelona, S.A., con los límites de esa cesión referidos a que el edificio hotelero se construya por la segunda en Barcelona o fuese un hotel que explotase directamente ésta y además efectuase dicho uso en un establecimiento selecto o de lujo, comprometiéndose a abstenerse de perturbar tal derecho.

44 Así lo establece el art. 47.1 LM, al señalar que: 1. La transmisión de la empresa en su totalidad implicará la de sus marcas, salvo que exista pacto en contrario o ello se desprenda claramente de las circunstancias del caso. En el mismo sentido lo establece el artículo 20.2 del Reglamento (UE) 2017/1001 del Parlamento Europeo y del Consejo de 14 de junio de 2017 sobre la marca de la Unión Europea.

45 GARBAYO BLANCH, J. Dos empresas y una misma marca, y... ¿ ilos consumidores? La libertad en la cesión de marcas al amparo de la sentencia del Tribunal Supremo de 13 de mayo de 2010. En: Gaceta jurídica de la Unión Europea y de la Competencia, 2010, no. 18, pp. 83-84.

46 Cabe añadir que en estos supuestos hablamos de cesión temporal ya que se ceden facultades plenas sobre la marca pero con obligación de retransmitir la marca al concluir el plazo pactado. Vid. LOBATO GARCÍA MIJAN, M. Propiedad industrial. En AA.VV. Memento práctico, Francis Lefebvre, 2011-2012, p. 274 .
} 
el negocio íntegramente. Si las partes han omitido la cesión en el contrato, puede entenderse, por un lado, que al operar la transmisión de la empresa tácitamente se presume que también se transmite la marca ${ }^{47}$. En consecuencia, el arrendatario, a partir de ese momento deberá también dejar de utilizar la marca. Lo relevante aquí será concretar en qué términos tendrá que dejar de hacer uso de ella. En puridad, opera de nuevo la transmisión, pero esta vez en sentido contrario, porque estamos ante un negocio jurídico de tracto único, la transmisión definitiva de la titularidad de la marca se agota en el propio momento de la cesión, de manera que lo que podemos entender como una devolución de la cesión dada es, en definitiva, un nuevo acto jurídico.

Esta última aclaración cobra más sentido si diferenciamos la mera cesión de la marca del contrato de licencia. Es importante tener en cuenta que la principal diferencia entre ambas figuras radica en que en la primera situación se produce una transferencia de la titularidad de la marca del cedente al cesionario, como hemos dicho ya, en un único acto, sin que el cedente pueda explotarla en el tiempo que dure el contrato. Sin embargo, en la licencia, se cede la facultad de uso de la marca dentro de unos límites, manteniéndose la titularidad de la misma en manos del licenciante ${ }^{48}$ de manera continuada por el tiempo acordado, entonces estaremos ante un acto de tracto sucesivo.

Los contratos de licencia de marca en la industria hotelera suelen tener mayor vinculación con otra clase de negocios jurídicos como son los de distribución y gestión, normalmente es un acuerdo que va aparejado al contrato de explotación con carácter instrumental ${ }^{49}$ reservándose la figura de la cesión para el arrendamiento de empresa.

\subsubsection{Precio cierto}

El pacto sobre el precio posee un apartado específico en el contrato acompañado del detalle de los diferentes conceptos por los que se comprometen a abonar honorarios. $\mathrm{El}$ art. $1543 \mathrm{CC}$ establece que el precio tiene que ser determinado y cierto. La determinación del precio no plantea problemas, ya que es un requisito imprescindible en cualquier tipo de contrato de explotación hotelera y en ningún caso puede ser aleatorio.

Sin embargo, el carácter de cierto sí da origen a discusiones. Algunos identifican el precio cierto con aquel determinado específicamente en el contrato, excluyendo la posibilidad de pactar un precio que consista en un porcentaje de los beneficios ${ }^{50}$. Otros se muestran a favor de la posibilidad de que las partes acuerden una contraprestación

\footnotetext{
47 CURTO POLO, M. La cesión de marca mediante contrato de compraventa, Cizur Menor: Aranzadi, 2002, p. 75 .

${ }^{48}$ Ibid., p. 212.

${ }^{49}$ Con frecuencia, si estamos ante cadenas hoteleras con marcado carácter internacional, la licencia de marca se documenta a través de un contrato separado, ya que la sociedad receptora de los cánones de licencia puede ser distinta a la que asume la gestión del hotel. Vid. LOZANO ROMERAL, SÁNCHEZ MONTERO y ENSEÑAT BILBAO. Naturaleza y estructura de los contratos de gestión en cadenas de hoteles. En AA.VV.2012 Práctica mercantil para abogados. Los casos más relevantes en 2011 en los grandes despachos, Madrid: La Ley, 2012.

50 Vid. doctrina enumerada por MESA MARRERO y LÓPEZ LÓPEZ, op. cit., p. 533. Según nuestra jurisprudencia, el precio cierto no significa que haya de establecerse mediante una cantidad fija, sino que basta que pueda determinarse a través de algún procedimiento lícito, sentencia del Tribunal Supremo (Sala $1^{\text {a) }}$ de 26 de enero de 1986; y, también, que no sea aleatorio o contingente, sentencias del Tribunal Supremo (Sala $1^{\text {a }}$ ) de 18 de abril de 1995 y(Sala $1^{\text {a }}$ ) 813/2008, de 25 de septiembre de 2008.
} 
mixta, entendiendo que en este caso le será de aplicación la regla contenida para la compraventa del art. $1446 \mathrm{CC}^{51}$.

En nuestra opinión el precio en este tipo de contratos debe considerarse cierto cuando se fija a expensas de un porcentaje de los beneficios de la explotación. A esta afirmación llegamos dado el marcado carácter mercantil que impregna el arrendamiento de una empresa hotelera y atendiendo a la costumbre en este negocio jurídico ${ }^{52}$. Ambas partes tienen la voluntad e intención de que su funcionamiento sea óptimo y alcance el mayor éxito posible. La realidad de este mercado y la costumbre nos demuestran la importancia de ofrecer libertad a las partes para fijar el precio de acuerdo a los criterios que mejor les beneficien.

A raíz de la última crisis económica, el modo en el que se establecía el importe del arrendamiento ha variado. Como consecuencia de la situación económica, en $2011^{53}$ la tendencia predominante fue la de combinar una renta fija con una variable, o toda variable, en función de la rentabilidad, de su facturación o bien de los beneficios netos que obtiene el arrendatario hotelero. Con la mejora de las perspectivas económicas y la recuperación del turismo, la tendencia se ha mantenido ${ }^{54}$.

El importe que acuerdan las partes, también se verá afectado por la necesaria inversión, en su caso, en las reformas para la mejora del establecimiento, ya sea por cumplimiento normativo o por la adaptación a las características del nuevo gestor. Si bien, hay que tener en cuenta que aquellas reparaciones necesarias de conservación del negocio para el uso preestablecido, corren a cargo del arrendatario y es una obligación que este contrae. Estos motivos pueden provocar que el importe varíe durante los primeros años, debido a la necesidad de amortizar la inversión realizada, y una vez alcanzada la fecha en la que se considera recuperada la inversión, se aplica el importe fijo o variable predeterminado.

\footnotetext{
51 MORALEJO IMBERNÓN, N.,op. cit. p. 3054.

52 En relación al precio cierto en los contratos de arrendamiento de industria y a las obligaciones que adquieren las partes, resulta interesante consultar el Pliego de Condiciones de la licitación del Contrato de arrendamiento para la gestión y explotación conjunta del Complejo del Palau de Congressos de Palma y el Hotel anejo. A pesar de que estamos en un ámbito de Derecho público, muchas de las cláusulas contenidas en dicho pliego se utilizan también en el sector privado. Así el plazo de duración de 15 años del contrato prorrogable año a año, hasta un máximo de 3 o bien el modo de fijar el precio del alquiler con un importe fijo y otro variable del $5 \%$ de los ingresos. Puede consultarse en el Expte. de contratación 02/2016,de la Empresa Pública Palau de Congressos de Palma, S.A.

${ }^{53}$ Junto al cambio en la fijación del precio del contrato, la crisis originó que las partes solicitaran la renegociación de los contratos en vigor, dada la modificación de las circunstancias bajo las que se fraguó la relación inicial. La intención de las cadenas hoteleras fue aplicar la cláusula rebus sic stantitbus para modificar el sistema de remuneración existente. Vid. FERNÁNDEZ CABANAS, J. Efectos de la sentencia Accor y nuevo escenario de la contratación en el sector hotelero. En: Revista de Derecho Patrimonial, no. 38, 2015, pp. 237-251.

${ }^{54}$ Según datos publicados por HALLÉ y GRAU. Informe de gestión de activos hoteleros. En: MAGMA Hospitality Consulting, Madrid, 2017, pp. 5 y 6:de las operaciones de alquiler realizadas, el 57\% se han firmado bajo el formato de alquiler variable y el $43 \%$ restante bajo la fórmula de renta fija. La tendencia al alza de los contratos de variable experimentada en años anteriores al 2015, se recupera en el año 2016 con un incremento del $4 \%$ con respecto al año 2015. En el año 2016, en el $76 \%$ de los contratos de alquiler fijo, la renta pactada se situó entre los 3.001€ y los $9.000 €$ habitación/año (siempre variando en función de la categoría y la ubicación del activo), con un aumento con respecto al periodo 2015 de algo más de 13 puntos porcentuales. Dentro de este rango, se han incrementado considerablemente los contratos entre $\operatorname{los} 6.000 €$ y $9.000 €$ habitación/año. Los contratos bajo el modelo de renta variable, se han basado, en el $62 \%$ de los casos, en un porcentaje sobre el total de los ingresos y el $38 \%$ restante en un porcentaje sobre el beneficio total de explotación.
} 
Otro de los aspectos que afectan al precio es el subarriendo. Las normas ${ }^{55}$ se han pronunciado sobre el subarriendo en los casos de arrendamiento de local de negocio, exigiendo el incremento de la renta que debe abonar el arrendatario en un $10 \%$ si espacial y en un $20 \%$ si es total ${ }^{56}$. En el supuesto del arrendamiento del negocio hotelero puede pactarse con el arrendador el subarriendo de determinadas unidades $o$ dependencias del establecimiento a terceros, piénsese por ejemplo en las tiendas, el gimnasio o el spa del hotel. En estos casos las partes acordarán el régimen de retribución que estimen oportuno. Normalmente no existe inconveniente en que el arrendatario subarriende esos espacios sin producir el incremento de la remuneración, recibiendo éste en su totalidad el importe de dicho subarriendo. Aunque en ese sentido podrá pactarse lo que se estime oportuno.

\subsubsection{Duración y término del contrato}

Dentro de las características de este contrato, citábamos la duración, que debe ser por un tiempo determinado ${ }^{57}$. Generalmente, el tiempo de arrendamiento del negocio hotelero es a largo plazo, no siendo inferior, en la mayoría de los casos, a los 10 años. Normalmente el plazo oscila entre los 10 y 15 años ${ }^{58}$, aunque también existen contratos con mayor duración que alcanzan los 25 años e incluso contratos que permiten la opción a compra transcurrido un plazo de tiempo o llegado el vencimiento ${ }^{59}$.

El pacto sobre la duración del contrato es un requisito esencial que deben acordar las partes. La tendencia en los últimos años en el caso de los contratos de explotación hotelera, ha sido la de disminuir el plazo de los contratos o la de incluir cláusulas que permitan la revisión de éstos cada cierto período de años. Los contratos han pasado de la rigidez de sus cláusulas de duración a la flexibilidad, permitiendo adaptarse a las circunstancias sobrevenidas e imprevistas. Los motivos que justifican estas decisiones son principalmente económicos, debido a los constantes cambios dela industria turística y a las variaciones que se producen en el mercado.

\footnotetext{
55 Ex art. 32.2 LAU.

56 CASAMITJANA OLIVÉ, FRANQUET SUGRAÑES y ORRIOLS SOTO. Modelos de estructura de propiedad y de gestión en el sector hotelero. En: Harvard Deusto Finanzas y Contabilidad, 2008, no. 86, p. 61 .

57 Cabe decir que en este tipo de negocios no tiene sentido el pacto de una duración indeterminada. Teniendo en cuenta que la transmisión de la empresa va aparejada a la del inmueble hotelero, imponer la duración indefinida del arriendo sería contrario a su naturaleza por cuanto supondría la transmisión para siempre del uso que se cede desmembrándolo del dominio, en términos que la delimitación del plazo es esencial en este negocio jurídico, debiendo en todo caso fijarse, bien señalando un período cierto y determinado o refiriéndolo a un acontecimiento futuro, pero que irremisiblemente ha de suceder. Esta argumentación es la utilizada para el caso del arrendamiento de local de negocio por ALBERRUCHE DÍAZFLORES, M. La resolución del contrato de arrendamiento por desistimiento unilateral. La cláusula penal. En: Actualidad Civil, no. 5, 2014, pp. 534 y ss.

58 Una aproximación a la duración media de los contratos de arrendamiento de empresa se ha extraído gracias al análisis de las transacciones hoteleras publicadas desde el año 2000 hasta2016 por la revista Hostel market, cuyo título se modifica a partir de 2015 a "Alimarket:Hoteles y Restauración”.

59 Así puede consultarse la Sentencia del Tribunal Supremo, (Sala 1ª) 445/2015, de 30 de abril de 2015, respecto al procedimiento entre las mercantiles Renta Turística y Urbana, S.L.U. y Tibesoca, S.L. El asunto versa sobre el ejercicio de una opción de compra sobre el Hotel La Residencia según se había previsto en el contrato de arrendamiento de local de negocio firmado por las partes. Desde 1995 se alquiló el hotel junto con la cesión de la explotación y la gestión por plazos de 4 años prorrogables anualmente, y se introdujo una cláusula permitiendo ejercitar la opción de compra si lo desea el arrendatario, siempre antes de una fecha determinada, enero de 2004.
} 
Una manera de mantener el éxito en la gestión es permitir la prórroga del contrato de forma tácita. En la mayoría de los casos esta prórroga va a ser de un tiempo más reducido al del periodo inicial, no llegando a alcanzar los 5 años.

Dentro de la duración del contrato, uno de los aspectos más relevantes, es el vencimiento. Una vez que se ha cumplido el plazo establecido en el contrato, el arrendatario está obligado a devolver la empresa tal y como la recibió ${ }^{60}$. En la configuración del contrato es sumamente importante detallar cómo se realizará la restitución de los bienes y la entrega del inmueble arrendado al vencimiento de éste. Normalmente las partes realizan una liquidación, tanto de la información contable y los flujos económicos como de los bienes, tras la revisión oportuna de los mismos.

La restitución del negocio en su totalidad, en los mismos términos que lo recibió el arrendatario es bastante difícil, ya que estamos ante un elemento vivo que va cambiando con el tiempo. Los elementos que existían en la formalización del contrato y persisten en su vencimiento, se deben restituir, con la obligación de indemnización por deterioro, siempre que se demuestre la culpa del arrendatario $^{61}$. Si se realizó un inventario, los bienes deben entregarse con las mismas características que se contemplan en él, a menos que hayan sido sustituidos. En ese caso, se entiende que se ha sustituido por otro bien de semejantes características y valor ${ }^{62}$. Así las cosas, serán las partes las que deberán decidir rigurosamente cómo se hará la devolución del negocio hotelero, con la mayor precisión posible.

\subsubsection{Responsabilidad por incumplimiento de las obligaciones contractuales}

Los contratos obligan al cumplimiento de lo pactado, el incumplimiento de alguna obligación originará el nacimiento de responsabilidad contractual de la parte incumplidora. A los daños producidos en el desarrollo de la relación jurídica le son de aplicación las normas de Derecho común sobre responsabilidad contractual. En todo caso, debemos seguir, entre otras, la regla contenida en el art. 1101 y ss. CC. Según el tenor literal del art. $1101 \mathrm{CC}$, quedan sujetos a indemnización por daños y perjuicios causados los que en el cumplimiento de sus obligaciones incurrieren en dolo, negligencia o morosidad, y los que de cualquier modo contravinieren al tenor de aquéllas.

El incumplimiento queda también legalmente amparado por el art. 1124CC. Dicho precepto permite al perjudicado por el incumplimiento de una obligación sin justa causa que opte entre exigir el cumplimiento de la misma o bien la resolución del contrato, con su consecuente abono de intereses y resarcimiento de daños. Hay que

\footnotetext{
${ }^{60}$ Debe restituirse la cosa al arrendador a la resolución del contrato en el tiempo fijado, tal y como exige el art. 1561, así como el art. 1565 CC. Nuestra jurisprudencia en el supuesto de ocupación del inmueble objeto del arrendamiento de industria por el exarrendatario, tras el transcurso del tiempo prefijado, entiende que cabe el desahucio según lo previsto en el art.1569 párrafo $1^{\circ} \mathrm{CC}$. Vid. sentencia del Tribunal Supremo (Sala 1 $1^{\text {a }}$ 885/2005, de 27 de octubre de 2005, resuelve el recurso contra la reclamación de indemnización por ocupación del objeto del arrendamiento de industria tras el transcurso del tiempo prefijado interpuesto por Kesa Hotel, B.V contra Hoteles Costa Blanca, S.A., habiendo existido una sentencia de desahucio previa a este procedimiento.

${ }^{61}$ VARA DE PAZ, N., op. cit., p. 89.

62 Vid. SÁNCHEZ CALERO y SÁNCHEZ-CALERO GUILARTE, Instituciones de Derecho Mercantil, vol. I, Aranzadi-Thomson Reuters, Cizur Menor, 2015, p. 320.
} 
tener en cuenta que en el sector hotelero es poco frecuente la exigencia del cumplimiento de la obligación cuando se ha producido un incumplimiento, debido al carácter personalísimo de la ejecución de la misma y la quiebra que se origina de la relación de confianza que existe entre las partes.

Las normas citadas se aplicarán en defecto de previsión expresa en el contrato aun constando, sean necesarias para facilitar su interpretación. Es recomendable que los negocios jurídicos fijen un tipo de régimen específico de responsabilidad por incumplimiento e identifiquen con claridad cuáles son los motivos que pueden dar lugar a la resolución del contrato $^{63}$. En la contratación vinculada a la explotación de establecimientos hoteleros, es habitual incluir un listado de causas que si operan producirán la resolución automática del contrato. En concreto, las más utilizadas en los contratos de arrendamiento de empresa son: una genérica relativa al incumplimiento de alguna de las obligaciones contenidas en el contrato si no las enmendase en un plazo determinado, la falta de adecuación del negocio para el ejercicio óptimo del mismo, la no realización de las mejoras y reparaciones necesarias para el buen funcionamiento del negocio hotelero, el deterioro y falta de ajuste al inventario inicial en la restitución del hotel, no adaptar tanto el continente como el contenido del hotel a los estándares e imagen de marca de la empresa ${ }^{64}$ o la resolución anticipada del contrato por falta de preaviso, entre otras.

La indemnización que nace fruto del incumplimiento, tal y como hemos dicho, corresponde a los daños y perjuicios ocasionados. Normalmente la parte incumplidora deberá indemnizar el daño emergente que haya provocado su acción sumado al importe que alcance su reparación pero además el lucro cesante de la misma. Es decir, habrá que añadir a la responsabilidad que se asume un porcentaje sobre los honorarios o beneficios que, según quien sea el perjudicado, se esperaban obtener en los años que restaban de contrato o el total de esas mismas cuantías limitadas a un período de tiempo, por ejemplo el año o los dos años siguientes al incumplimiento del contrato.

\section{BIBLIOGRAFÍA}

ALBERRUCHE DÍAZFLORES, M. La resolución del contrato de arrendamiento por desistimiento unilateral. La cláusula penal. En: Actualidad Civil, no. 5, 2014, pp. 534-540.

ALCOVER GARAU, G. Aproximación al régimen jurídico del contrato de gestión hotelera. En: Revista de Derecho Mercantil, 2000, no. 237, pp. 1003-1026.

\footnotetext{
63 El incumplimiento debe serlo de una obligación principal, o un incumplimiento esencial de una obligación secundaria. En todo caso, en el contrato se suelen detallar las obligaciones consideradas esenciales cuyo incumplimiento pueda dar lugar a la resolución del contrato. MARTÍNEZ CAÑELLAS, A. El contrato de gestión hotelera. En MORILLAS JARILLO, PERALES VISCASILLAS y PORFIRIO CARPIO (dirs.) Estudios sobre el futuro Código Mercantil: libro homenaje al profesor Rafael Illescas Ortiz, Madrid: Universidad Carlos III, 2015, p. 1507.

${ }^{64}$ En esta línea podemos traer a colación la controversia surgida por una conocida empresa hotelera (Tryp S.A.) que suscribe un contrato con una cláusula del siguiente tenor literal: «la arrendataria hace constar en este acto que es conocedora de esta anomalía y que asume a su costa la instalación de estas bocas de agua en las plantas del edificio». La cadena hotelera resulta demandada por no cumplir con dicha obligación y por tanto se insta la resolución del contrato. Vid. sentencia Audiencia Provincial de Madrid (Sección 18 ${ }^{\mathrm{a}}$ ) de 26 de abril de 2001.
} 
ALONSO SOTO y SÁNCHEZ ANDRÉS. Los contratos de colaboración. En MENÉNDEZ Y ROJO (dirs.) Lecciones de Derecho Mercantil, vol. II, Cizur Menor: Thomson-Civitas, 2016, pp. 97-114.

BROSETA PONT, M. La transmisión de la empresa: Compraventa y arrendamiento. En: Revista de Derecho Mercantil, 1968, no. 107 pp. 59-106.

BROSETA PONT y MARTÍNEZ SANZ, Manual de Derecho Mercantil, vol. II, Madrid: Tecnos, 2016.

CASAMITJANA OLIVÉ, FRANQUET SUGRAÑES y ORRIOLS SOTO. Modelos de estructura de propiedad y de gestión en el sector hotelero. En: Harvard Deusto Finanzas y Contabilidad, 2008, no. 86, pp. 56-63.

COSTAS RODAL, L. Contratos de cesión temporal de uso y disfrute. En BERCOVITZ RODRÍGUEZ-CANO, R. (Dir.)Tratado de Contratos, vol. II, Valencia: Tirant lo Blanch, 2013, pp. 2645-3199.

CURTO POLO, M. La cesión de marca mediante contrato de compraventa, Cizur Menor: Aranzadi, 2002.

EVANOFF, M. The international hotel management agreement: Origins, evolution, and status. En: Cornell Hospitality Report, 2016, no. 11, pp. 3-15.

FERNANDEZ BARCALA y GONZÁLEZ DÍAZ. Elección de la forma organizativa en las cadenas hoteleras: El caso de Sol Meliá. En: Papers de turismo. 2006, no. 39, pp. 25-43.

FERNÁNDEZ CABANAS, J. Efectos de la sentencia Accor y nuevo escenario de la contratación en el sector hotelero. En: Revista de Derecho Patrimonial, no. 38, 2015, pp. 237-251.

FERNÁNDEZ MARTÍN, D. La promoción inmobiliaria: aspectos prácticos, Madrid: Cie Inversiones Editoriales Dossat, 2005.

FONT GALÁN y PAGADOR LÓPEZ. La empresa como objeto de negocios jurídicos. En: JIMÉNEZ SÁNCHEZ y DÍAZ MORENO (coords.), Derecho Mercantil, vol. I, Madrid: Marcial Pons, 2013, pp. 195-224.

GARBAYO BLANCH, J. Dos empresas y una misma marca, y... ¿los consumidores? La libertad en la cesión de marcas al amparo de la sentencia del Tribunal Supremo de 13 de mayo de 2010. En: Gaceta jurídica de la Unión Europea y de la Competencia, 2010, no. 18, pp. 83-84.

GARCÍA CANTERO, G. Arrendamiento de empresa: aspectos civiles y mercantiles. En: Actualidad laboral, 1996, no. 1, pp. 277-295.

GARCÍA GARNICA, M.C., El régimen jurídico del Leasing Financiero Inmobiliario en España, Pamplona: Aranzadi, 2001.

GONZÁLEZ-BUENO, C. Artículo 47. Transmisión de la marca. En GONZÁLEZ-BUENO, C. (coord.) Comentarios a la Ley y Reglamento de Marcas, Madrid: Civitas, 2003.

HALLÉ y GRAU. Informe de gestión de activos hoteleros. En: MAGMA Hospitality Consulting, Madrid, 2017, pp. 5 y 6

HERNANDO CEBRIÁ, L. La transmisión de la empresa a través de distintos contratos. En: Revista de Derecho Mercantil, 2001, no. 242, pp. 1871-1942. 
ÍNIIGUEZ ORTEGA, P. El contrato de gestión hotelera, Valencia: Tirant lo Blanch, 2015.

LOBATO GARCÍA MIJAN, M. Propiedad industrial. En AA.VV. Memento práctico, Francis Lefebvre, 2011-2012.

LOZANO ROMERAL, SÁNCHEZ MONTERO y ENSEÑAT BILBAO. Naturaleza y estructura de los contratos de gestión en cadenas de hoteles. En AA.VV. 2012 Práctica mercantil para abogados. Los casos más relevantes en 2011 en los grandes despachos, Madrid: La Ley, 2012.

MARTÍNEZ CAÑELLAS, A. El contrato de gestión hotelera. En MORILLAS JARILLO, PERALES VISCASILLAS y PORFIRIO CARPIO (dirs.) Estudios sobre el futuro Código Mercantil: libro homenaje al profesor Rafael Illescas Ortiz, Madrid: Universidad Carlos III, 2015, pp. 1485-1510.

MARTÍNEZ SANZ, PALAU RAMÍREZ y MONTEAGUDO MONEDERO. Comentario a la Ley sobre el Contrato de Agencia, Madrid: Civitas, 2000.

MESA MARRERO y LÓPEZ LÓPEZ. El arrendamiento de empresa. En YZQUIERDO TOSLADA, M. (dir.) Contratos: civiles, mercantiles, públicos, laborales e internacionales, con sus implicaciones tributarias, vol. III, Navarra: AranzadiThomson Reuters, 2014, pp. 523-588.

MORALEJO IMBERNÓN, N. El arrendamiento de empresa. Pamplona: Aranzadi, 2004.

- Contratos de cesión temporal de uso y disfrute. El arrendamiento de empresa. En BERCOVITZ RODRÍGUEZ-CANO, R. (Dir.) Tratado de Contratos, vol. II, Valencia: Tirant lo Blanch, 2013, pp. 2645-3199.

MOTOS GUIARO, M. El arrendamiento de empresa. En AA.VV., Estudios jurídicos en homenaje a Joaquín Garrigues, Madrid: Tecnos, 1971, pp. 482-502.

PAGADOR LÓPEZ, J. La empresa. En: JIMÉNEZ SÁNCHEZ, G. (coord.) Nociones de Derecho Mercantil, Madrid: Marcial Pons, 2016, pp. 19-24.

PASTOR y LOEDA. 200 Ediciones de Alimarket Hoteles y Restauración. En: Alimarket: Hoteles y Restauración, 2017, no. 200, pp. 6-11.

PAYNE y PERRET. Hotel franchising in Europe. En: Informe HVS London, 2014.

PEINADO GRACIA, J.I. Las obligaciones mercantiles. En JIMÉNEZ SÁNCHEZ y DÍAZ MORENO (coords.) Derecho Mercantil, vol. V, Madrid: Marcial Pons, 2013, pp. 27-62.

PÉREZ-SERRABONA GONÁLEZ, J. Arrendamientos mercantiles. En JIMÉNEZ SÁNCHEZ y DÍAZ MORENO (coords.) Derecho Mercantil, vol. V, Madrid: Marcial Pons, 2013, pp. 263-314.

PÉREZ MORIONES, A. El contrato de gestión hotelera, Valencia: Tirant lo Blanch, 1998.

ROJO, A. El establecimiento mercantil. En MENÉNDEZ Y ROJO (dirs.) Lecciones de Derecho Mercantil, vol. I, Navarra: Thomson-Civitas, 2016, pp. 83-116.

SÁNCHEZ CALERO y SÁNCHEZ-CALERO GUILARTE. Instituciones de Derecho Mercantil, vol. I, Cizur Menor: Aranzadi-Thomson Reuters, 2015. 
SERRANO DE HARO, FERNÁNDEZ y CHANCE. Nuevo régimen de las Sociedades Anónimas Cotizadas de Inversión en el Mercado Inmobiliario (SOCIMIs): cuestiones prácticas a tener en cuenta en la implementación del régimen. En: AA.VV., 2014 Práctica Fiscal para Abogados, Madrid: Dykinson, 2014.

VARA DE PAZ, N. El arrendamiento de empresa. En: Cuadernos de derecho y comercio, 1988, no. 4, 49-92.

VILATA MENADAS, S. El tratamiento de la sucesión empresarial en el traspaso de unidades empresariales: una visión jurisprudencial. En: Revista de Derecho Concursal y Paraconcursal, 2008, no. 8, pp. 491-508. 